\title{
Cirrhotic cardiomyopathy: the liver affects the heart
}

\author{
M.V.H. Carvalho (id) ${ }^{1}$, P.C. Kroll $\mathbb{1}^{2}$, R.T.M. Kroll $\mathbb{B}^{3}$ and V.N. Carvalho (i) ${ }^{4}$ \\ ${ }^{1}$ Departamento de Cirurgia, Faculdade de Medicina de Jundiaí, Jundiaí, SP, Brasil \\ ${ }^{2}$ Hospital de Transplante E.J. Zerbini, São Paulo, SP, Brasil \\ ${ }^{3}$ Instituto Dante Pazzanese de Cardiologia, São Paulo, SP, Brasil \\ ${ }^{4}$ Hospital Municipal Dr. Mario Gatti, Campinas, SP, Brasil
}

\begin{abstract}
Cirrhotic cardiomyopathy historically has been confused as alcoholic cardiomyopathy. The key points for diagnosis of cirrhotic cardiomyopathy have been well explained, however this entity was neglected for a long time. Nowadays the diagnosis of this entity has become important because it is a factor that contributes significantly to morbidity-mortality in cirrhotic patients. Characteristics of cirrhotic cardiomyopathy are a hyperdynamic circulatory state, altered diastolic relaxation, impaired contractility, and electrophysiological abnormalities, particularity QT interval prolongation. The pathogenesis includes impaired function of beta-receptors, altered transmembrane currents and overproduction of cardiodepressant factors, such as nitric oxide, cytokines and endogenous cannabinoids. In addition to physical signs of hyperdynamic state and heart failure under stress conditions, the diagnosis can be done with dosage of serum markers, electrocardiography, echocardiography and magnetic resonance. The treatment is mainly supportive, but orthotopic liver transplantation appears to improve this condition although the prognosis of liver transplantation in patients with cirrhotic cardiomyopathy is uncertain.
\end{abstract}

Key words: Cirrhotic cardiomyopathy; Cirrhosis; Heart failure; Cardiac cirrhosis; Hyperdynamic circulation

\section{Introduction}

For many years, cardiac dysfunctions associated with liver cirrhosis were attributed to the direct toxic effects of alcohol on the heart. However, in 1953, Kowalski and Abelmann (1) showed the existence of a circulatory dysfunction specific to liver cirrhosis. Since then, several studies have consistently reproduced those findings (2-5). Successive publications of experimental and clinical studies have established the idea that cirrhotic cardiomyopathy (CCM) is a clinical entity different from that seen in alcoholic heart muscle disease.

Interference of liver disease with the cardiac and circulatory performance would be expected, considering that the liver receives $25 \%$ of the cardiac output. The term CCM was introduced more than three decades ago to describe a spectrum of chronic cardiac dysfunction in cirrhotic patients in the absence of known heart disease, regardless of the etiology of cirrhosis $(4,6)$.

Hepatic cirrhosis leads to a hyperdynamic circulatory state, which induces cardiac dysfunctions that characterize the CCM syndrome. This syndrome includes, in addition to the hyperdynamic circulation, a combination of systolic (7) and diastolic dysfunctions (8-11), prolonged ventricular repolarization (12), and inability of the sinus node to increase heart rate $(\mathrm{HR})$ during exercise (13).

\section{Epidemiology and natural history}

CCM is a condition easily tolerated, remaining asymptomatic for months to years because of the near-normal cardiac function at rest, manifesting only under conditions of physical or pharmacological stress. Therefore, the diagnosis of CCM is difficult and the exact prevalence of this condition remains unknown (7).

However, it has been estimated that $40-50 \%$ of patients who underwent liver transplantation have some signs of cardiac dysfunction, which means that these patients underwent surgery under a condition of CCM $(7,11,14)$. Furthermore, since diagnosis of CCM is frequently missed or delayed, its natural history is unclear in terms of response to treatment and prognosis (7).

As CCM is a relatively recent entity, the purpose of this review is to provide an explanation about its definition. Its pathophysiological mechanisms, criteria, and supplemental exams for its diagnosis are also included to show $\mathrm{CCM}$ relevance. Although the treatment of this condition is mainly supportive, the actions that should be taken to approach CCM are also commented. 


\section{Material and Methods}

Structured medical subject headings (MeSH) were used to search original articles and reviews about CCM in MEDLINE by means of the PubMed database. The term "cirrhotic cardiomyopathy" was used. A total of 275 complete articles, published until March 2018, were identified. All articles selected in the search were in English, and abstracts for oral presentations and letters to the editor were ignored. We also searched for further relevant articles in the reference lists of articles. First, titles and abstracts were read to know whether they fit the purpose of reviewing the issue. If their eligibility remained unclear, the full-text reports were then considered. Ninety studies were selected and organized to provide the authors of the present study with the means to write a narrative review including history, definition, epidemiologic data, clinical findings, diagnosis, and treatment.

\section{Definition of CCM}

A consensus diagnostic criterion for CCM (Table 1) was established at the World Congress of Gastroenterology held in Montreal in 2005 (10). Thus, CCM is defined as a cardiac dysfunction in patients with cirrhosis, which is characterized by impaired contractile responsiveness to stress and/or altered diastolic relaxation, with electrophysiological abnormalities, in the absence of other known cardiac disorder $(9,10)$.
These diagnostic criteria are still in use. However, suggestions have been made to improve these criteria by including the dysfunction of the right ventricle as an important parameter of cardiac damage caused by cirrhosis (15). Tissue Doppler and speckle tracking imaging have also shown that CCM patients have biventricular diastolic dysfunction at rest, larger left and right atria, and higher systolic pulmonary arterial pressure and left ventricular mass (16). In addition, the systolic function assessment using tissue strain imaging is more sensitive than the usual echocardiographic indices (17).

Because alcoholism is the leading cause of hepatic cirrhosis, it is important not to confuse CCM with alcoholic cardiomyopathy, whose underlying mechanisms responsible for structural and functional cardiac abnormalities are pathophysiologically and clinically different (18). The main mechanism responsible for alcoholic cardiomyopathy is the reduction in arterial perfusion of the whole organism, which leads to hypoxia and passive venous congestion secondary to increased systemic venous pressure (19).

\section{Pathophysiological mechanisms}

Although the major circulatory changes that lead to CCM were indicated more than half a century ago, these mechanisms have been more clearly understood only recently. Figure 1 shows a summary of the mechanisms involved in the genesis of CCM hyperdynamic circulation.

Table 1. Proposal of diagnostic criteria for cirrhotic cardiomyopathy agreed upon at the 2005 World Congress of Gastroenterology in Montreal (10). There are suggestions (not included in this table) to improve these criteria considering dysfunction of right ventricle (15), biventricular diastolic dysfunction at rest, large left and right atria, higher systolic pulmonary arterial pressure and left ventricular mass (16) and evaluate systolic function assessment using tissue strain imaging (17).

\begin{tabular}{ll}
\hline Systolic dysfunction & $\begin{array}{l}\text { Resting ejection fraction }<55 \% \\
\text { Blunted increase in cardiac output with exercise or pharmacological stimuli }\end{array}$ \\
Diastolic dysfunction & $\begin{array}{l}\text { Early diastolic atrial filling ratio (E/A ratio) }<1.0 \text { (age corrected) } \\
\text { Deceleration time (DT) }>200 \mathrm{~ms} \\
\text { Prolonged isovolumetric relaxation time }>80 \mathrm{~ms}\end{array}$ \\
Supportive criteria & $\begin{array}{l}\text { Electrophysiological abnormalities (prolongation of QT) } \\
\text { Abnormal chronotropic response } \\
\text { Electromechanical uncoupling } \\
\text { Enlarged left atrium } \\
\text { Increased myocardial mass } \\
\text { Increased brain natriuretic peptide and pro-peptide } \\
\text { Increased troponin I }\end{array}$ \\
\hline
\end{tabular}

\section{References}

10. Wiese et al. doi: 10.1038/nrgastr.2013.210.

15. Chen Y et al. doi: 10.1016/j.jjcc.2015.08.001.

16. Rimbas RC et al. doi: 10.1016/j.ultrasmedbio.2017.11.013.

17. Farr M and Schulze PC. doi: 10.4137/CMC.S15722. 

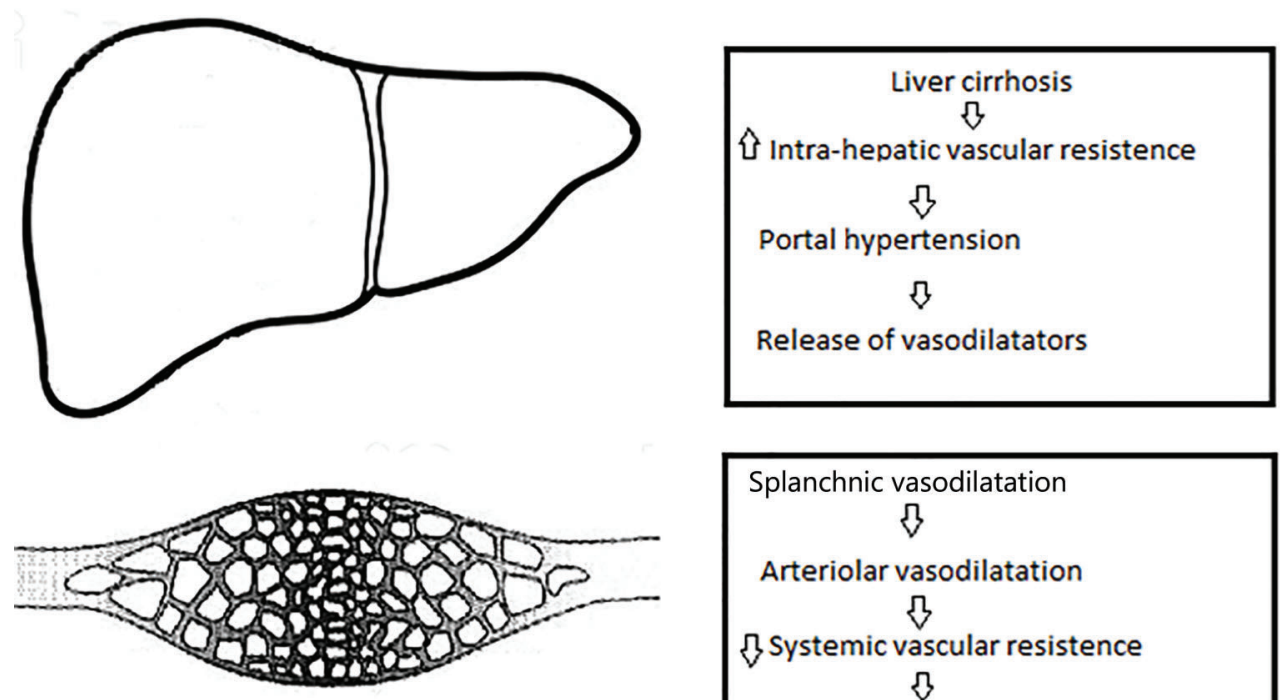

Splanchnic vasodilatation

\&

Arteriolar vasodilatation

约

\{Systemic vascular resistence

$\Omega$

Effective central hypovolemia

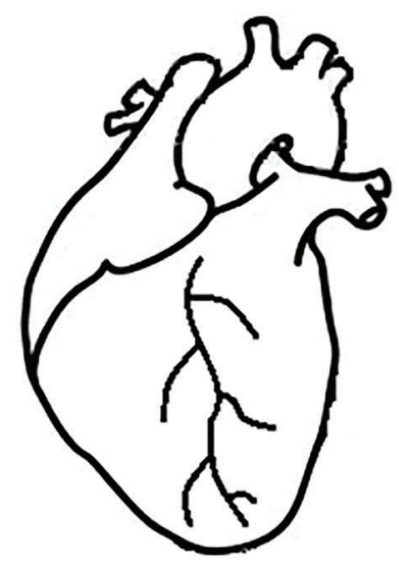

Hyperdynamic circulation

ß

îCO 仓िHR ßुAPßSVR

Uि Adrenergic Hyperactivity

î Angiotensin II

iि Aldosterone

Figure 1. Schematic representation of the pathophysiological mechanisms that lead to liver disease to affect the heart. CO: cardiac output; HR: heart rate; AP: arterial pressure; SVR: systemic vascular resistance.

Portal hypertension leads to a state of peripheral vasodilatation due to a release of vasodilator mediators such as nitric oxide (NO), carbon monoxide, and prostacyclin (20-22).

Progressive hepatic decompensation results in blood volume redistribution, with increased splanchnic blood flow and relatively decreased central circulation. The baroreceptors may be deactivated to compensate for the reduction in the central and arterial blood flow, with increased sympathetic nervous activity and consequent increase in HR and cardiac output (CO) (23). Therefore, hyperdynamic circulation in cirrhosis is an appropriate initial response to the splanchnic arterial vasodilation (24).

Patients with advanced cirrhosis exhibit hyperdynamic circulation with increased $\mathrm{CO}$. This hyperdynamic state arises from a marked splanchnic arterial vasodilation and reduced systemic vascular resistance (25). Increase in vasodilation due to portosystemic shunting and bacterial translocation increase the hyperdynamic circulation and central hypovolemia (26).

At rest, the intra-cardiac pressures are normal because the reduced afterload secondary to the systemic vasodilation compensates for both preload reduction and contractile dysfunction. This circulatory state, which resembles those of high $\mathrm{CO}$, results from increased blood flow and is defined as heart failure due to volume overload. Thus, the hyperdynamic circulation in cirrhosis is secondary to the low systemic vascular resistance and increased arterial compliance (27-30). 


\section{Systolic dysfunction}

Several studies have shown that the left ventricular ejection fraction is normal at rest $(25,30)$. Nevertheless, the ventricular ejection fraction after exercise increases significantly less than in non-cirrhotic patients $(31,32)$. The aerobic exercise capacity and maximal HR in cirrhotic patients are lower than in normal subjects. This reduced cardiac performance is due to the direct low HR response to exercise (33), decreased myocardial contractility, and marked weakening and loss of the skeletal musculature, thus causing impaired extraction of and demand for peripheral oxygen (34). Systolic incompetence has been evidenced by physical and pharmacological stress tests (9). The mechanism is related to the myocardial low response in the downregulation of beta-adrenergic receptors in cardiomyocyte membranes (35).

Other inhibitory pathways contribute to decrease the cardiomyocyte contractility and, hence, decrease the systolic function in cirrhosis. Usually, the cannabinoid signaling system is minimally expressed in healthy individuals. However, a significant upregulation of the cannabinoid signaling pathway is observed in patients with cirrhosis (36). In addition, increase in the activity of inducible NO synthase and heme oxygenase promotes the production of NO and carbon monoxide, respectively, and these evanescent gases have a negative effect on cardiomyocyte contraction. Stimulation of the NO pathway is possibly related to the increased activity of cytokines in cirrhosis, as it was observed in the experimental model of cirrhotic rats (37). Furthermore, bacterial lipopolysaccharides that permeate the gut barrier enter into circulation and activate monocytes and lymphocytes to release various cytokines (30).

In summary, various studies have shown that the left ventricular ejection fraction is usually normal in patients with chronic liver disease who are at rest. In this condition, the reduced afterload, which is secondary to systemic vasodilation, compensates the preload reduction and contractile dysfunction. However, systolic dysfunction is unmasked under stress situations. Thus, cirrhotic cardiomyopathy is characterized by normal or high cardiac output. However, systolic dysfunction occurs when the heart is challenged. In such condition, the heart is unable to maintain adequate arterial circulation.

\section{Diastolic dysfunction}

Diastolic dysfunction is characterized by a decreased rate of left ventricular relaxation, restricted blood flow into the ventricle, and increased end-diastolic pressure. According to Glenn et al. (38), alteration of titin protein modulation and collagen configuration have a role in the pathogenesis of diastolic dysfunction in cirrhosis. Titin protein is a sarcomere protein that directly influences the ventricular stiffness and diastolic function. In addition, some studies indicate that sodium and fluid retention in cirrhosis may play a role in the development of diastolic dysfunction (39-41).
Prevalence and extent of systolic dysfunction in cirrhotic patients is variable whereas various elements of diastolic dysfunction are more frequent (42). Other authors have pointed out that some degree of diastolic dysfunction is present in all patients $(8,10)$. Unlike systolic dysfunction, which appears in stress conditions, diastolic dysfunction can be easily seen in the echocardiography exam at rest $(42,43)$.

In the World Congress of Gastroenterology 2005 (10), however, some criticism was directed at the criteria in relation to the transmitral flow velocities calculated using conventional pulse-wave Doppler echocardiography. That was because transmitral velocities calculated using a conventional pulse-wave Doppler have neither sensitivity nor specificity for diagnosis and grading severity of diastolic dysfunction (44).

Thus, tissue Doppler imaging could be considered to quantify left ventricular diastolic function (18). Speckle tracking is a new echocardiography technique that can offer a detailed analysis of ventricular function. It allows frame-to-frame tracking of myocardial tissue in the longitudinal, radial, and circumferential directions, providing a detailed analysis of left ventricular function (45).

Cirrhotic patients primarily manifest diastolic dysfunction with normal systolic function at rest (43). In cirrhosis, diastolic dysfunction derives from myocardial wall thickening, which is caused by left ventricular hypertrophy, altered collagen structure, fibrosis, and subendothelial edema, resulting in high left ventricular filling pressures $(8,10,46)$. In a study with cirrhotic patients, Wong et al. (47) reported that diastolic dysfunction is of marked and decisive importance in CCM, and diastolic dysfunction affects at least $50 \%$ of patients with cirrhosis. Doppler imaging studies have shown correlation between diastolic and circulatory dysfunctions, development of ascites, hepatorenal syndrome, and survival (48-50).

\section{Electrocardiographic abnormalities and chronotropic incompetence}

Prolonged QT interval is the most common electrophysiological alteration, occurring in more than $50 \%$ of cirrhotic patients $(51,52)$. This abnormality can affect the heart rhythm causing serious arrhythmias, including ventricular arrhythmia and sudden death (53).

Loss and/or dysfunction of the membrane potassium channels play a role in delayed ventricular repolarization, which may lead to QT interval prolongation (54). However, the pathophysiology of QT interval prolongation in cirrhosis has not yet been fully elucidated $(55,56)$. Certainly, exposure of the heart to cardiotoxins such as endotoxins, cytokines, and bile salts also plays an important role in increasing the sympathetic-adrenergic tone that characterizes cirrhosis $(57,58)$. The QT interval prolongation surely also results from hyperactivity of the sympatheticadrenergic discharges, since excessive release of noradrenaline causes myocardial damage and beta-adrenergic receptor downregulation (59). A study showed that, 
in cirrhotic patients, duration of ventricular repolarization (represented by the QT interval) varies in response to minimal changes in portal pressure (58).

Chronotropic incompetence is the inability of the sinus node to increase HR after exercise or pharmacological stimulation. In CCM and under stress conditions, the sympathetic nervous system is not able to respond with adequate acceleration of the atrial and ventricular rate (60). The mechanism of this autonomic dysfunction is probably a direct inhibition of the beta-receptor mediated stimulation (61).

\section{Diagnosis of CCM}

CCM is a relatively silent condition under stable situations. Peripheral vasodilation protects the heart by reducing the afterload and heart failure does not appear at rest. In patients suffering from cirrhosis, with intolerance to exercise and without underlying known cardiac disease, CCM should be suspected.

Although new exams are improving diagnosis accuracy, echocardiogram and electrocardiogram are essential exams to diagnose this condition.

Electrocardiogram. Prolongation of the QTC interval ( $>440 \mathrm{~ms}$ ) can be observed in cases of portal hypertension with or without cirrhosis. The frequency of QT prolongation in cirrhotic patients is in the range of $30-60 \%$ and positively correlates with the severity of liver disease $(62,63)$.

As heart rate affects the length of the QT interval, its correction by the heart rate is always necessary. Thus, applying the Fridericia' formula instead of the Bazett formula is preferable as the latter incompletely suppresses the relationship between QT and heart rate (64).

Echocardiography. Echocardiography is essential in all patients with suspicion of CCM. In contrast with systolic dysfunction, diastolic dysfunction is a prominent characteristic of CCM and seems to be its first manifestation (65). In addition, diastolic impairment may affect the prognosis of cirrhotic patients regardless if liver was transplanted or not (48). The most frequent echocardiography abnormality is first-degree diastolic dysfunction. It is characterized by reduced early diastolic ventricular filling and increased atrial filling $(E / A<1.0)$, deceleration time $>200 \mathrm{~ms}$, and prolonged isovolumetric relaxation time (ITVR $>80 \mathrm{~ms}$ ), which represent increased resistance to ventricular inflow (66).

Stress echocardiography is a method that should be used in patients with advanced liver disease as it can detect subtle systolic and diastolic dysfunctions before the ventricular ejection fraction is decreased. This stress test should be considered in the diagnostic approach to CCM to avoid under-diagnosis (67).

Cardiac troponin. The structural protein troponin is a specific marker of myocardial lesion. Troponin I is a thin filament of cardiac muscle protein, which is a marker of cardiac lesions. The levels of such marker are elevated in patients with ischemia. Patients with liver cirrhosis can present high levels of troponin I $(68,69)$.
Cardiac biomarkers (ANP and BNP). The atrial natriuretic peptide (ANP) is secreted in response to volumetric atrial distention, as a result of atrial overload and ventricular hypertrophy in cirrhotic patients. As patients with uncompensated cirrhosis usually exhibit changes in volume and cardiac pressures, the ANP is frequently elevated in these cases (70).

The brain natriuretic peptide (BNP) and its pro-hormones are also produced by the ventricles as a consequence of volume overload, increase in ventricular pressure, and ischemia (71). BNP and its pro-hormones are usually elevated in patients with cirrhosis (72), and BNP is considered an early marker in CCM (73).

Supplemental exams, which can contribute to the diagnosis of CCM, are presented below.

Cardiovascular magnetic resonance (MR). Until now, MR is considered the best exam to study heart morphology. In addition, MR with gadolinium contrast can be used to determine the chamber volumes, ejection fraction, and possible fibrosis and edema (11). The MR imaging areas of high signal intensity, which appear 10-15 min after injection of gadolinium (intracellular contrast agent) in regions of myocardial scarring, were described as late gadolinium enhancement. In case of CCM, late gadolinium enhancement has a diffuse myocardial distribution in MR images with the appearance of myocarditis $(74,75)$. Furthermore, MR images can indicate an impaired cardiac response under pharmacological stress testing with dobutamine. Deformation analysis parameters of MR images may be more sensitive than conventional methods in identifying abnormalities in the inotropic response to stress (76).

\section{Controversial issues}

In patients with liver cirrhosis, cardiac dysfunction may be related to arterial hypertension and ischemic and alcoholic heart disease. Hepatic disease may likewise cause anemia, which also affects cardiac structure and function. Therefore, the relationship between cirrhosis and cardiac disease cannot be assured (77).

\section{Treatment of CCM}

CCM is a clinically silent or mild entity, and symptoms of heart failure become evident when stress occurs. Thus, there is little interest or necessity in treating CCM at the asymptomatic stage. As far as is known, there is no clinical study on the management of CCM. When some form of stress occurs, and heart failure clinically manifests, the guidelines for the treatment of chronic heart failure in non-cirrhotic patients can be followed. However, in advanced phases of cirrhosis, reduction in cardiac afterload is not recommended, as these patients are already significantly vasodilated (78).

Liver transplantation can be a definitive treatment for patients with cirrhosis, but the unavailability of organ 
donors and cost concerns should be considered. The candidates must be well evaluated, as patients are at risk of death by heart failure, coronary artery disease, tachyarrhythmias, and other cardiac deaths in the post-operative term of liver transplantation. Thus, there are no accurate data on prognosis for liver transplantation in patients with CCM. However, diastolic dysfunction significantly worsens after transplantation in these patients (79).

Patients with CCM should be recommended to avoid physical effort and other forms of stress, and oxygen should be provided in some situations. Medications can have adverse effects or weak response in patients with CCM, and specific pharmacological treatment with proven efficacy in CCM is not currently available now. However, when some form of stress occurs and heart failure becomes evident, the guidelines for treatment of chronic heart failure can be followed at least in the pre-ascites phase.

Non-selective beta-blockers have shown to reduce the prolonged QT interval and might reduce the hyperdynamic load in patients with cirrhosis, but whether the correction of QT interval has a positive effect on prognosis is doubtful (80). In addition, the use of beta-blocker drugs by patients with refractory ascites has a risk of increased mortality (81). Furthermore, patients with cirrhosis cardiomyopathy received a six-month therapy with metoprolol, and betablockage with this drug did not improve heart function and morphology (82).

In a revision of 10 hemodynamic studies on liver cirrhosis, Tripathi and Hayes (83) concluded that carvedilol is a potent agent to reduce portal pressure. However, careful dosing is necessary to minimize adverse effects, especially reduction in the mean arterial pressure. Doses as low as $12.5 \mathrm{mg}$ have shown an efficacy that is similar to that of higher doses, and probably represent the best compromise between efficacy and side effects.

Angiotensin converting enzyme inhibitors can improve diastolic function in patients with cirrhosis by decreasing the ventricular thickness and dilation, but they should be used in the early phases of cirrhosis because of the risk of hypotension and hepatic-renal syndrome in later phases (84). Even though these drugs reduce the portal pressure in patients with cirrhosis, they should be discontinued if ascites appears, as they can further aggravate the systemic vasodilation state and increase the risk of hepatorenal syndrome $(18,85)$.

\section{References}

1. Kowalski HJ, Abelmann WH. The cardiac output at rest in Laennec's cirrhosis. J Clin Invest 1953; 32: 1025-1033, doi: $10.1172 / \mathrm{JCl} 102813$.

2. Murray JF, Dawson AM, Sherlock S. Circulatory changes in chronic liver disease. Am J Med 1958; 24: 358-367, doi: 10.1016/0002-9343(58)90322-X.

3. Kontos HA, Shapiro W, Mauck HP, Patterson Jr JL. General and regional circulatory alterations in cirrhosis of the liver.
Spironolactone is a competitive aldosterone inhibitor and should be used as a diuretic in patients with severe heart failure as it has been shown to reduce the frequency of hospitalization and mortality (86). In addition, aldosterone receptor antagonists seem to reduce the hepatic-venous pressure gradient, the ventricular wall thickness, and the left ventricular end-diastolic volume $(86,87)$.

Liver transplant is the only effective treatment established for patients with final stage liver disease associated with CCM. Liver transplantation has been shown to reverse the systolic and diastolic dysfunction and prolonged QT interval (88).

However, many cardiac complications and some cardiac deaths have been reported in patients undergoing liver transplantation. This fact can be attributed to cardiac dysfunction due to previous CCM (89).

Unfortunately, no reliable method to identify patients susceptible to develop perioperative cardiac complications is currently available (29).

\section{Conclusions}

Liver cirrhosis can induce cardiac abnormalities characterized by an impaired stress response, diastolic dysfunction, and electrocardiographic changes (CCM). No symptom is seen at rest, but heart failure can be unmasked under stress conditions. This occurs because at rest the diastolic and systolic dysfunctions are counterbalanced by the specific hyperdynamic state of cirrhosis. Pathogenesis of CCM includes mechanisms such as increased activity of the vasodilator pathway through the actions of NO, carbon monoxide, cytokines, and cannabinoids, decreased beta-adrenergic function, and sodium and calcium transport kinetics downregulation in the cardiac muscle, leading to an impaired contractile function of the cardiomyocyte. Echocardiogram and the electrocardiogram are the most important exams for diagnosis of CCM, but cardiac magnetic resonance imaging and biomarkers are currently becoming more relevant than before.

The treatment of $\mathrm{CCM}$ is directed to left ventricular failure, with sodium restriction, diuretics, and afterload reduction. Liver transplantation may improve or normalize cardiac function.
Americ J Medic 1964; 37: 526-535, doi: 10.1016/0002-9343 (64)90066-X.

4. Caramelo C, Fernandez-Muñoz D, Santos JC, Blanchart A, Rodriguez-Puyol D, López-Novoa JM, et al. Effect of volume expansion on hemodynamics, capillary permeability and renal function in concious, cirrhotics rats. Hepatology 1986; 6: 129-134, doi: 10.1002/hep.18400 60125. 
5. Maroto A, Arroyo V, Ginès A, Saló J, Claria J, Jiménez W, et al. Brachial and femoral artery blood flow in cirrhosis: relationship to kidney dysfunction. Hepatology 1993; 17: 788-793, doi: 10.1002/hep.1840170707.

6. Lee SS. Cardiac abnormalities in liver cirrhosis. West $\mathrm{J}$ Med 1989; 151: 530-535

7. Zardi EM, Abbate A, Zardi DM, Dobrina A, Margiotta D, Van Tassel BW, et al. Cirrhotic Cardiomyopathy. J Am Coll Cardiol 2010; 56: 539-549, doi: 10.1016/j.jacc.2009.12.075.

8. Cazzaniga M, Salerno F, Pagnossi G, Dionigi E, Visentin S, Cirelloo I, et al. Diastolic dysfunction is associated with poor survival in cirrhotic patients with transjugular intrahepatic portosystemic shunt. Gut 2007; 56: 869-875, doi: 10.1136/ gut.2006.102467.

9. Moller S, Dumcke CW, Krag A. The heart and the liver. Expert Rev Gastroenterol Hepatol 2009; 3: 51-64, doi: 10.1586/ 17474124.3.1.51.

10. Wiese S, Hove JD, Bendtsen F, Moller S. Cirrhotic cardiomyopathy: pathogenesis and clinical relevance. Nat Rev Gastroenterol Hepatol 2014; 11: 177-186, doi: 10.1038/ nrgastro.2013.210.

11. Gassanov N, Caglayan E, Semmo N, Messenkeil G, Er F. Cirrhotic cardiomyopathy: a cardiologist's perspective. World J Gastroenterol 2014; 20: 15492-15498, doi: 10.3748/wjg. v20.i42.15492.

12. Bernardi M, Maggioli C, Dibra V, Zaccherini G. QT interval prolongation in the liver cirrhosis: innocent by stander or serious threat? Expert Rev Gastroenterol Hepatol 2012; 6: 57-66, doi: 10.1586/egh.11.86.

13. Henriksen JH, Fuglsang $\mathrm{S}$, Bendtsen $\mathrm{F}$, Christensen $\mathrm{E}$, Moller S. Dyssynchronous electrical and mechanical systole in patients with cirrhosis. $J$ Hepatol 2002; 36: 513-520, doi: 10.1016/S0168-8278(02)00010-7.

14. Rahman S, Mallet SV. Cirrhotic cardiomyopaty: implications for the perioperative management of liver transplant patients. World J Hepatol 2015; 7: 507-520, doi: 10.4254/ wjh.v7.i3.507.

15. Chen Y, Chan AC, Chan SC, Chok SH, Sharr W, Fung J, et al. A detailed evaluation of cardiac function in cirrhotic patients and its alteration with or without liver transplantation. J Cardiol 2016; 67: 140-146, doi: 10.1016/j.jjcc.2015. 08.001.

16. Rimbas RC, Baldea SM, Guerra RDGA, Visoiu SI, Rimbas $M$, Pop CS, et al. New definition criteria of myocardial dysfunction in patients with liver cirrhosis: a speckle tracking and tissue Doppler imaging study. Ultrasound Med Biol 2018; 44: 562-574, doi: 10.1016/j.ultrasmedbio.2017.11. 013.

17. Farr M, Schulze PC. Recent advances in the diagnosis and management of cirrhosis-associated cardiomyopathy in liver transplant candidates: advanced echo imaging cardiac biomarkers, and advanced heart failures therapies. Clin Med Insights Cardiol 2015; 8(Suppl 1): 67-74, doi: 10.4137/CMC. S15722.

18. Wong F. Cirrhotic cardiomyopathy. Hepatol Int 2009; 3: 294 304, doi: 10.1007/s12072-008-9109-7.

19. Rafie IM, Colucci WS. Alcoholic Cardiomyopathy. www. uptodate.com [Access on August 13, 2018]

20. Cahill PA, Redmond EM, Rodges R, Zhang S, Sitzmann JV. Increased endothelial nitric oxide synthase activity in the hyperemic vessels of portal hypertensive rats. J Hepatol 1996; 25: 370-378, doi: 10.1016/S0168-8278(96)80124-3.

21. Morita T, Perella MA, Lee ME, Kourembanas S. Smooth muscle cell-derived carbon monoxide is a regulator of vascular cGMP. Proc Natl Acad Sci USA 1995; 92: 14751479, doi: 10.1073/pnas.92.5.1475.

22. Goldberg DS, Fallon MB. Lung and heart disease secondary to liver disease. Clin Gastroenterol Hepatol 2015; 13: 21182127, doi: 10.1016/j.cgh.2015.04.024.

23. Moller S, Henriksen JH. Cirrhotic cardiomyopathy: a pathophysiological review of circulatory dysfunction in liver disease. Heart 2002; 87: 9-15, doi: 10.1136/heart.87.1.9.

24. Henriksen JH, Fulsang S, Bendtsen F, Christensen E, Moller S. Arterial compliance in patients with cirrhosis: stroke volume-pulse pressure ratio as simplified index. $A m \mathrm{~J}$ Physiol Gastrointest Liver Physiol 2001; 280: G584-G594, doi: 10.1152/ajpgi.2001.280.4.G584.

25. Friedman HS, Fernando $H$. Ascite as a marker for the hyperdynamic heart of the Laennec's cirrhosis. Alcohol Clin Exp Res 1992; 16: 968-970, doi: 10.1111/j.1530-0277.1992. tb01902.x.

26. Wiest R, Lawson M, Geukin M. Pathological bacterial translocation in liver cirrhosis. J Hepatol 2014; 60: 197-209, doi: 10.1016/j.jhep.2013.07.044.

27. Moller S, Henriksen $\mathrm{HH}$. Circulatory abnormalities in cirrhosis with focus on neuro-humoral aspects. Semin Nephrol 1997; 17: 505-519.

28. Moller S, Henriksen JH. Cardiovascular complications of cirrhosis. Gut 2008; 57: 268-278, doi: 10.1136/gut.2006. 112177.

29. Timoh T, Protano MA, Wagman G, Bloom M, Vittorio TJ. A perspective on cirrhotic cardiomyiopathy. Transplant Proc 2011; 43: 1649-1653, doi: 10.1016/j.transproceed.2011. 01.188 .

30. Moller S, Bendtsen F. The pathophysiology of arterial vasodilatation and hyperdynamic circulation in cirrhosis. Liver Int 2018; 38: 570-580, doi: 10.1111/liv.13589.

31. Kelbaek H, Elriksen J, Brynolf I, Raboel A, Lund JO, Bonnevie $O$, et al. Cardiac performance in patients with assymtomatic alcoholic cirrhosis of the liver. Am J Cardiol 1984; 54: 852-855, doi: 10.1016/S0002-9149(84)80220-9.

32. Kelbaek H, Rabol A, Brynof I, Eriksen J, Bonnevie O, Godfredsen J, et al. Haemodynamic response to exercise in patients with alcoholic liver cirrhosis. Clin Physiol 1987; 7: 35-41, doi: 10.1111/j.1475-097X.1987.tb00631.x.

33. Grose RD, Nolan J, Dillon JF, Errington M, Hannan WJ, Bouchier IA, et al. Exercise-induced left ventricular dysfunction in alcoholic and non-alcoholic cirrhosis. J Hepatol 1995; 22: 326-332, doi: 10.1016/0168-8278(95)80286-X.

34. Epstein SK, Ciubotaru RL, Ziberberg MD, Kaplan LM, Jacoby C, Freeman R, et al. Analysis of impaired exercise capacity in patients with cirrhosis. Dig Sis Sci 1998; 43: 1701-1707, doi: 10.1023/A:1018867232562.

35. Lee SS, Marty J, Mantz J, Samain E, Braillon A, Lebrec D. Desensitization of myocardial beta-adrenergic receptors in cirrhotic rats. Hepatology 1990; 12: 481-485, doi: 10.1002/ hep.1840120306.

36. Caraceni P, Domenicalli M, Bernardi M. The endocannabinoid system and liver diseases. J Neuroendocrinol 2008; 20(Suppl 1): 47-52, doi: 10.1111/j.1365-2826.2008.01679.x. 
37. Liu H, Ma Z, Lee SS. Contribution of nitric oxide to the pathogenesis of cirrhotic cardiomyopathy in bile duct-ligated rats. Gastroenterology 2000; 118: 937-944, doi: 10.1016/ S0016-5085(00)70180-6.

38. Glenn TK, Honar H, Liu H, ter Kreus HEDJ, Lee SS. Role of cardiac myofilament proteins titin and collagen in the pathogenesis of diastolic dysfunction in cirrhotic rats. J Hepatol 2011; 55: 1249-1255, doi: 10.1016/j.jhep.2011. 02.030 .

39. Fields NG, Yuan BX, Leenen FH. Sodium-induced cardiac hypertrophy. Cardiac sympathetic activity versus volume load. Circ Res 1991; 68: 745-755, doi: 10.1161/01.RES.68. 3.745 .

40. Takeda $\mathrm{Y}$, Yoneda T, Demura M, Miyamori I, Mabuchi H. Sodium-induced cardiac aldosterone synthesis causes cardiac hypertophy. Endocrinology 2000; 141: 1901-1904, doi: 10.1210/endo.141.5.7529.

41. Chayanupatkul M, Liangpunsaku S. Cirrhotic cardiomyopathy: review of pathophysiology and treatment. Hepatol Int 2014; 8: 308-315, doi: 10.1007/s12072-014-9531-y.

42. Baik SK, Fouad TR, Lee SS. Cirrhotic cardiomyopathy. Orphanet J Rare Dis 2007; 2: 15, doi: 10.1186/1750-1172-2-15.

43. Ruiz-del-Árbol L, Serradilla R. Cirrhotic cardiomyopathy. World J Gastroenterol 2015; 21: 11502-11521, doi: 10.3748/ wjg.v21.i41.11502.

44. Karagiannakis DS, Papatheodoridis G, Vlachogiannakos J. Recent Advances in cirrhotic cardiomyopathy. Dig Dis Sci 2015; 60: 1141-1151, doi: 10.1007/s10620-014-3432-8.

45. Galderisi M, Lomoriello VS, Santoro A, Esposito R, Olibet M, Raia $R$, et al. Differences of myocardial systolic deformation and correlates of dyastolic function in competitive rowers and young hypertensives: a speckle-tracking echocardiography study. J Am Soc Echocardiogr 2010; 23: 1190-1198, doi: 10.1016/j.echo.2010.07.010.

46. Pozzi M, Caruso S, Boari G, Pecci V, de Ceglia S, Magglioni $S$, et al. Evidence of functional and structural cardiac abnormalities in cirrhotic patients with and without ascites. Hepatology 1997; 26: 1131-1137, doi: 10.1002/hep.510260507.

47. Wong F, Liu P, Lilly L, Bomzon A, Blendis L. Role of cardiac structural and functional abnormalities in the pathogenesis of hyperdynamic circulation and renal sodium retention in cirrhosis. Clin Sci 1999; 97: 259-267, doi: 10.1042/cs0970259.

48. Ripoll C, Catalina MV, Yotti R, Olmedilla L, Pérez-Peña J, Lo lacono $\mathrm{O}$, et al. Cardiac dysfunction during liver transplantation: incidence and preoperative predictors. Transplantation 2008; 85: 1766-1772, doi: 10.1097/TP.0b013e318172c936.

49. Ruiz-del-Arbol, Achecar L, Serradilla R, Rodriguez Gandia MÁ, Rivero M, Garrido E, et al. Diastolic ysfunction is a predictor of poor utcomes in patients cirrhosis, portal hypertension, and normal creatinine. Hepatology 2013; 58: 1732-1741, doi: 10.1002/hep.26509.

50. Naqvi IH, Mahmood K, Naeem M, Vashwani AS, Ziaullah S. The heart matters when the liver shatters! Cirrhotic cardiomyopathy: frequency, comparison, and correlation with severity of disease. Prz Gastroenterol 2016; 11: 247-256, doi: $10.5114 / \mathrm{pg} .2016 .57962$

51. Lazzeri C, La Villa G, Laffi G, Vecchiarino S, Gambilonghi F, Gentilini $P$, et al. Autonomic regulation of the heart rate and QT interval in nonalcoholic cirrhoisis with ascites. Digestion 1997; 58: 580-586, doi: 10.1159/000201505.
52. Bernardi M, Maggioli C, Dibra V, Zaccherini G. QT interval prolongation in the liver cirrhosis: innocent bystander or serious threat? Expert Ver Gastroenterol Hepatol 2012; 6: 57-66, doi: 10.1586/egh.11.86.

53. Day CP, James OF, Butler TJ, Campbell RW. QT prolongations and sudden cardiac death in patients with alcoholic liver disease. Lancet 1993; 341: 1423-1428, doi: 10.1016/ 0140-6736(93)90879-L.

54. Batchvarov V, Camm AJ, Gersh BJ, Downey BC. QT dispersion: Measurement and interpretation. www.uptodate. com [Access on April 17, 2018]

55. Páll A, Czifra Á, Vitális Z, Papp M, Gyorgy P, Szabó Z. Pathophysiological and clinical approach to cirrhotic cardiomyopathy. J Gastrointestin Liver Dis 2014; 23: 1-9, doi: 10.15403/jgld.2014.1121.233.apac.

56. Mozos I. Arrytmia risk in liver cirrhosis. World $J$ Hepatol 2015; 7: 662-672, doi: 10.4254/wjh.v7.i4.662.

57. Ytting $\mathrm{H}$, Henriksen JH, Fulglsang $\mathrm{S}$, Bendtsen $\mathrm{F}$, Moller $\mathrm{S}$. Prolonged Q-T(c) interval in mild portal hypertensive cirrhosis. J Hepatol 2005; 43: 637-644, doi: 10.1016/j.jhep. 2005.04.015.

58. Genovesi S, Prata Pizzala DM, Pozzi M, Ratti L, Milanese $\mathrm{M}$, Pieruzzi F, et al. QT interval prolongation and decrease heart rate variability in cirrhotic patients: relevance of hepatic venous pressure gradiente and serun calcium. Clin Sci 2009; 116: 851-859, doi: 10.1042/CS20080325.

59. Ma Z, Meddiings JB, Lee SS. Membrane physical properties determine cardiac beta-adrenergic receptor function in cirrhotic rats. Am J Physiol 1994; 267: G87-G93, doi: 10.1152/ ajpgi.1994.267.1G87.

60. Wong F, Girgrah N, Graba J, Allidina Y, Liu P, Blendis L. The cardiac response to exercise in cirrhosis. Gut 2001; 49 : 268-275, doi: 10.1136/gut.49.2.268.

61. Hendrikse MT, Tiger DR. Peripheral and cardiovascular autonomic impairment in chronic liver disease: prevalence and relation to hepatic function. $J$ Hepatol 1992; 16: 177-183, doi: 10.1016/S0168-8278(05)80112-6.

62. Bernardi M, Calandra S, Colantoni A, Trevisan F, Raimondo $\mathrm{ML}$, Sica $\mathrm{G}$, et al. Q-T interval prolongation in cirrhosis: prevalence, relantionship with severity, and etiology of the disease and possible pathogenetic factors. Hepatology 1998; 27: 28-34, doi: 10.1002/hep.510270106.

63. Gaskari S, Honar H, Lee SS. Therapy insight: cirrhotic cardiomyopathy. Nat Clin Prat Gastroenterol Hepathol 2006; 3: 329-337, doi: 10.1038/ncpgasthep0498.

64. Moller S, Bernardi M. Interactions of the heart and the liver. Eur Heart J 2013; 34: 2804-2811, doi: 10.1093/eurheartj/ eht246.

65. Pozzi M, Redaeli E, Ratti L, lli G, Guidi C, et al. Time-course of diastolic dysfunction in different stages of chronic HCV related liver diseases. Minerva Gastroenterol Dietol 2005; 51: 179-186.

66. Licata A, Novo G, Colomba D, Tuttolomondo A, Galia M, Camma C. Cardiac involvement in patients with cirrhosis: a focus on clinical features and diagnosis. $J$ Cardiovasc Med 2016; 17: 26-36, doi: 10.2459/JCM.0000000000000288.

67. Barbosa M, Guardado J, Marinho C, Rosa B, Quelhas I, Lourenço A, et al. Cirrhotic cardiomyopathy: isn't stress evaluation always required for diagnosis? World $\mathrm{J}$ Hepatol 2016; 28: 200-206, doi: 10.4254/wjh.v8.i3.200. 
68. Pateron $\mathrm{D}$, Bane $\mathrm{P}$, Laperche $\mathrm{T}$, Logeard $\mathrm{D}$, Lefilliare $\mathrm{P}$, Sogni $\mathrm{P}$, et al. Elevated circulating cardiac troponin $\mathrm{I}$ in patients with cirrhosis. Hepatology 1999; 29: 640-643, doi: 10.1002/hep.510290332.

69. Yang YY, Lin HC. The heart: Pathophysiology and clinical implications of cirrhotic cardiomyopathy. J Chin Med Assoc 2012; 75: 619-623, doi: 10.1016/j.jcma.2012.08.015.

70. Ginès $P$, Jiménez W, Arroyo V, Navassa M, Lopez C, Tito L, et al. Atrial natriuretic factor in cirrhosis with ascites: plasma levels, cardiac release and splanchnic extraction. Hepatology 1988; 8: 636-642, doi: 10.1002/hep.1840080333.

71. Yamamoto $K$, Burnett Jr CJ, Jougasaki M, Nishimura RA, Bayley KR, Saito $Y$, et al. Superiority of brain natriuretic peptide as a hormonal marker of ventricular systolic and diastolic dysfunction and ventricular hypertrophy. Hypertension 1996; 28: 988-994, doi: 10.1161/01.HYP.28.6.988.

72. Henrisen JH, Gotze JP, Fuglsang S, Christensen E, Bendtsend $F$, Moller $S$. Increase circulating pro-brain natriuretic peptide (proBNP) in patients with cirrhosis: relation to cardiovascular dysfunction and severity of disease. Gut 2003; 52 : 1511-1517, doi: 10.1136/gut.52.10.1511.

73. Wong F, Siu S, Liu P, Blendis LM. Brain natriuretic peptide: is it a predictor of cardimyopathy in cirrhosis? Clin Sci 2001; 101: 621-628, doi: 10.1042/cs1010621.

74. Kim DH, Choi SI, Chang HJ, Choi DJ, Lim C, Park JH. Delayed hyperenhancement by contrast-enhanced magnetic resonance imaging: clinical application for various cardiac diseases. J Comput Assist Tomogr 2006; 30: 226232, doi: 10.1097/00004728-200603000-00011.

75. Lossnitzer D, Steen H, Zahn A, Lehrke S, Weiss C, Weiss $\mathrm{KH}$, et al. Myocardial late gadolinium enhancement cardiovascular magnetic resonance in patients with cirrhosis. $J$ Cardiovasc Magn Reson 2010; 12: 47, doi: 10.1186/1532429X-12-47.

76. Sampaio F, Lamata P, Bettecourt N, Alt SC, Ferreira N, Kowallick JT, et al. Assessment of cardiovascular physiology using dobutamine stress cardiovascular magnetic resonance reveals impaired contractile reserve in patients with cirrhotic cardiomyopathy. J Cardiovasc Magn Reson 2015; 17: 61, doi: 10.1186/s12968-015-0157-6.

77. Pellicori P, Torromeo C, Callichia A, Ruffa A, Di lorio M, Cleland JG, et al. Does cirrhotic cardiomyopathy exist? 50 years of uncertainty. Clin Res Cardiol 2013; 102: 859-864, doi: 10.1007/s00392-013-0610-1.
78. Moller S, Hove JD, Dixen U, Bendtsen F. New insights into cirrhotic cardiomyopathy. Int J Cardiol 2013; 167: 11011108, doi: 10.1016/j.jijcard.2012.09.089.

79. Sonny A, Ibrahim A, Schuster A, Jaber WA, Cywinski JB. Impact and persistence of cirrhotic cardiomyopathy after liver transplantation. Clin Transplant 2016; 30: 986-993, doi: 10.1111/ctr.12778.

80. Zambruni A, Trevisan F, Di Micoli A, Saveli F, Berzigotti A, Bracci $E$, et al. Effect of cirrhotic beta-blockade on QT interval in patients with liver cirrhosis. $J$ Hepatol 2008; 48: 415-421, doi: 10.1016/j.jhep.2007.11.012.

81. Sersté T, Melot C, Francoz C, Durand F, Rautou PE, Valla D, et al. Deleterious effect of beta-blockers on survival in patients with cirrhosis and refractory ascites. Hepatology 2010; 52: 1017-1022, doi: 10.1002/hep.23775.

82. Silvestre $O$, Farias $A Q$, Ramos $D$, Furtado MS, Rodrigues $A$, Ximenes RO, et al. B-blocker therapy for cirrhotic cardiomyopathy: a ramdomised-controled trial. Eur $\mathrm{J}$ Gastroenterol Hepatol 2018; 30: 930-937, doi: 10.1097/MEG.0000000 000001128.

83. Tripathi D, Hayes PC. The role of carvedilol in management of portal hypertension. Eur J Gastroenterol Hepatol 2010; 22: 905-911, doi: 10.1097/MEG.0b013e3283367a99.

84. Bos R, Mougenot N, Findji O, Vanhoute PM, Lechat $P$. Inhibition of catecholamine-induced cardiac fibrosis by an aldosterone antagonist. J Cardiovasc Pharmacol 2005; 45: 8-13, doi: 10.1097/00005344-200501000-00003.

85. Tsochatzis EA, Bosch J, Burroughs AK. New therapeutic paradigm for patients with cirrhosis. Hepatology 2012; 56: 1983-1992, doi: 10.1002/hep.25915.

86. Pozzi M, Grassi G, Ratti L, Favini G, Dell' Oro R, Redaeli E, et al. Cardiac, neuroadrenergic, and portal hemodynamic effects of prolonged aldosterone blockage in postviral child a cirrhosis. Am J Gastroenterol 2005; 100: 1110-1116, doi: 10.1111/j.1572-0241.2005.41060.x.

87. Al Hamoudi W, Lee SS. Cirrhotic cardiomyopathy. Ann Hepatol 2006; 5: 132-139.

88. Torregrosa M, Aguadé S, Dos L, Segura R, Gónzalez A, Evangelista A, et al. Cardiac alterations in cirrhosis: reversibily after liver transplantation. J Hepatol 2005; 42: 68-74, doi: 10.1016/j.jhep.2004.09.008.

89. Liu H, Jayakumar S, Traboulsi M, Lee SS. Cirrhotic cardiomyopathy: implications for liver transplantation. Liver Transp 2017; 23: 826-835, doi: 10.1002/It.24768. 